\title{
Mass is more: The conceiving of (un)countability and its encoding into language in 5-year-old-children
}

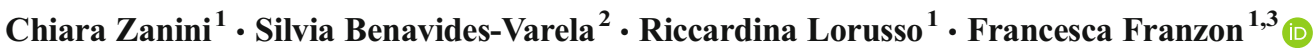

Published online: 3 November 2016

(C) Psychonomic Society, Inc. 2016

\begin{abstract}
Is the mass-count distinction merely a linguistic issue, or is it coded in representations other than language? We hypothesized that a difference between mass and count properties should be observed even in absence of linguistic distinctions driven by the morphosyntactic context. We tested 5-6-year-old children's ability to judge sentences with mass nouns (sand), count nouns (ring), and neutral nouns (i.e., those that appear in mass and count contexts with similar frequency; cake). Children refused neutral nouns embedded in uncountable morphosyntactic contexts, showing a preference for a count interpretation. This suggests that linguistic features alone are not sufficient to define the mass-count distinction. Additional analyses showed that children's performance with mass - but not count-morphosyntax correlated with their performance in tasks concerning logical and conservation operations. Altogether, these results suggest that the processing of mass features is not more demanding than count features from a linguistic point of view; rather, mass features entail additional abstraction abilities.
\end{abstract}

Keywords Count/mass distinction · Language acquisition · Morphological number $\cdot$ Conservation operations · Countability

Francesca Franzon

francescafranzon7@gmail.com

1 Department of Neuroscience DNS, University of Padova, Via Giustiniani 5, 35128 Padova, Italy

2 Department of Developmental Psychology and Socialization DPSS, University of Padova, Via Venezia 12/2, 35131 Padova, Italy

3 Department of Linguistic and Literary Studies DiSLL, University of Padova, Piazzetta Folena 1, 35137 Padova, Italy
Traditional grammar descriptions (after Cheng, 1973) trace a division between mass and count nouns. Specifically, mass nouns refer to substances (e.g., sand), and count nouns refer to objects (e.g., ring). Morphosyntactic properties are crucial to distinguish between these two categories of nouns: Mass nouns do not take the plural (e.g., sands) and in the singular form cannot be modified by some determiners (e.g., a sand, each sand). Count nouns do have a plural form (e.g., rings) and in the singular form can be modified by those determiners (e.g., a ring, each ring).

Even though the properties that distinguish mass from count nouns have been debated for a long time, both by philosophers (e.g., Pelletier, 1975, 2012; Quine, 1960) and linguists (e.g., Allan, 1980; Bale \& Barner, 2009; Gillon, 1992; Jackendoff, 1991), influential linguistic approaches (e.g., Borer, 2005; Chierchia, 1998, 2010; De Belder, 2011) agree that mass nouns (or mass morphosyntax) are formally simpler than count nouns (or count morphosyntax). The argument is that the computation of these latter requires more operations at the morphosyntactic level or at the semantic level. In fact, mass nouns can appear only in the singular (e.g., sand) while count nouns display a full inflection for number morphology (e.g., ring vs. rings). Even in the philosophical perspective advanced by Quine (1960), the mass interpretation would be the basic one from which the count interpretation derives.

However, as already observed in many theoretical works (e.g., Allan, 1980; Pelletier, 2012; Rothstein, 2010), the simplicity of mass nouns as compared to count nouns in linguistics does not seem as straightforward in terms of cognition. The assumption that mass nouns (or mass morphosyntax) are formally simpler than count nouns (or count morphosyntax) should imply that the 
former require less cognitive processing than the latter. Instead, various psycholinguistic studies in different populations show that the processing of mass nouns and mass morphosyntax is more demanding. Young children acquire the count morphosyntax (i.e., the use of "many") before the mass morphosyntax (i.e. the use of "much"; Gathercole, 1985). Eye-tracking data collected on adult speakers showed a disadvantage for count nouns appearing in mass morphosyntactic context, but not in the converse case (Frisson \& Frazier, 2005). Adults show longer response times (RTs) in mass than count nouns (Gillon, Kehayia, \& Taler, 1999; Mondini, Kehaya, Gillon, Arcara, \& Jarema, 2009) and display latency differences in the event-related potential (ERP) components associated with the two types of noun in lexical decision (El Yagoubi et al., 2006; Mondini et al., 2008) and judgment tasks (Steinhauer, Pancheva, Newman, Gennari, \& Ullman, 2001). Furthermore, mass nouns require more processing in the frontal lobe (associated with greater cognitive effort) than count nouns (Semenza, El Yagoubi, Mondini, Chiarelli, \& Venneri, 2008, p. 6).

Notably, some studies failed to find any clear dissociation in mass versus count processing (for a review, see Semenza et al., 2008). Noteworthy, to our knowledge no experiment has ever reported longer response times or inferred a more demanding processing for count nouns (or count morphosyntax) with respect to mass nouns (or mass morphosyntax), as the linguistics and philosophical accounts would predict.

Intrigued by the discrepancy between experimental and formal accounts, in this study we hypothesized that even though mass morphosyntax might imply fewer operations at the linguistic level, its processing might be more demanding from a cognitive point of view. It is certainly the case that both count reference and mass reference entail abstract reasoning to generalize a class from an incidental entity and accordingly name the latter. In this process, shape and, more generally, boundaries are a pivotal cue (e.g., Landau, Smith, \& Jones, 1988, 1992), particularly for what concerns count references (Samuelson \& Smith, 1999). Conversely, in mass references the boundaries of an entity are not denoted and they are not a reliable cue. As properties like boundaries are present in every perceived occurrence of an entity, we hypothesized that mass reference implies more abstraction abilities with respect to count reference. In particular, mass reference should entail a deeper involvement of cognitive processes linked to logical operations such as deduction, abstraction, conservation. These operations allow the conceiving of entities (e.g., milk) without relying on their shape boundaries (e.g., a glass of milk, a bottle of milk), thus resulting in mass references. Crucially, the implementation of logical operations becomes efficient only throughout development (e.g., Vianello \& Marin, 1997), which should affect the use of mass, but not count, references in young children.

Our hypothesis finds support on developmental studies that have explored the mass and count issue not only from a linguistic point of view but also from a more cognitive perspective, in particular concerning the children's knowledge of objects and substances, typically associated (though not completely overlapping) to count and mass nouns respectively. Works by Soja, Carey, and Spelke (1991) and Soja (1992) showed that, before mastering count or mass morphosyntax, English-speaking children at the age of 2 years can discriminate objects from substances by relying on perceptual information of the entities. Therefore, mastering the object-substance distinction does not necessarily imply that the mass and count morphosyntax has been acquired (Imai \& Gentner, 1997). Soja (1992) reported that morphosyntactic cues with respect to novel nouns can influence 21/2-year-old children's referring to novel entities. However, the perceptual properties of the referent over the morphosyntactic properties of the noun modulate its interpretation as an object or a substance; a linguistic label of mass or of count assigned to the referent is not necessary to define it as an object or a substance (Soja, 1992). Moreover, some studies have found that the ability to discriminate objects from substances, at least for what concerns their tracking and quantification, is prelinguistic and present by at least 10 months of age (i.e., before most children are producing their first words; Hespos, Ferry, \& Rips, 2009; vanMarle \& Wynn, 2011; for a review, see Hespos \& vanMarle, 2012). However, some specific cognitive biases in early word learning seem to favor objects over substances. While acquiring the lexicon, children are likely to assume a new word to refer to a whole object, not to the substance or parts of the object (for a review, see Bloom \& Kelemen, 1995; Markman, 1990). Some studies dealing with a similar dichotomy, namely the comparison between solid and nonsolid entities, did not report such a preference: children rely on overall similarity when generalizing names for nonsolid entities, in contrast to the well-established use of shape similarity when generalizing names for solid things (Samuelson \& Horst, 2007). However, no study, at least to our knowledge, has reported a bias toward substances over objects. This predilection for objects might in turn disfavor the most prototypical mass nouns. In fact, when a peculiar class of mass nouns, namely "object-mass" nouns referring to objects are presented (e.g., furniture, luggage) young children overextend the count morphosyntax to refer to them (Barner \& Snedeker, 2005), suggesting a strong bias in favor of the count nouns (or the count morphosyntax). 
Frequency is another factor that might explain the apparent facilitation in the processing of count nouns with respect to mass nouns. Children learn the mass and count distinction either through semantic exposure, namely on the basis of the frequency with which a noun occurs as referring to either individuals or nonindividuals (Bloom, 1999), or through the co-occurrence of the various nouns in a specific morphosyntactic context (Barner \& Snedeker, 2005, 2006; Gordon, 1985). Some studies have successfully prevented such bias by designing tasks exploiting only novel words, that is, items all equally unfamiliar to the infants (i.e. Soja, 1992). However, to our knowledge, no previous study has measured and controlled for the frequency with which the real-word stimuli chosen in experimental settings are used in mass contexts with respect to count context in the spoken language. ${ }^{1}$ This leaves unresolved the question of whether, after controlling for frequency, the formal simplicity of the mass nouns (and mass morphosyntax) in terms of linguistics actually has its parallel in cognition.

Besides these two factors, it is also possible that some suboptimal choices in the experimental designs have influenced the results in previous literature. In particular, the visual modality of presentation of stimuli in linguistic tasks could per se be a bias in favor of a count interpretation. More specifically, an unbiased representation of mass nouns should not explicitly depict the boundaries of the referent in order to test any linguistic distinction concerning this category. On the one side it is true that being an object does not imply an individual reference (i.e., Bloom, 1999), and that also properties such as function may play a role in assigning mass or count morphosyntax to words, as suggested in a study focused on aggregates conducted by Middleton, Wisniewski, Trindel, and Imai (2004). On the other side, however, it is equally reasonable to think that when something is displayed as having physical boundaries, the perception of such boundaries influences the conceiving it as an object (i.e., Chesney \& Gelman, 2015; Prasada, Ferenz, \& Haskell, 2002; vanMarle \& Scholl, 2003), thus favoring a count interpretation. Therefore, a study aimed at testing mass and count issue from a strictly linguistic perspective could be better designed avoiding potentially biasinducing pictures in the experimental material.

\footnotetext{
${ }^{1}$ Notably, some studies on corpora have shown that the distribution of nouns is not polar with respect to their occurrence preferentially within one of the two contexts; however, some nouns occur more than others within mass or count morphosyntax (Katz \& Zamparelli, 2012; Kulkarni, Rothstein, \& Treves, 2013; Zanini, Arcara, \& Franzon, 2014).
}

\section{The present study}

We developed an orally administered experimental task in which the mass and count morphosyntax was manipulated and the frequency of occurrence of nouns as mass or count was controlled. The so designed Mass and Count Test (MACT) assesses the children's ability to judge sentences with mass and count nouns. Mass and count nouns were presented in congruent or incongruent contexts. In congruent contexts, a noun that is most frequently used as mass appeared in a mass morphosyntax and in incongruent contexts a noun that is most frequently used as mass appeared in a count morphosyntax; the reverse holds for count nouns.

The aim was twofold. First, we aimed at investigating whether the mass versus count distinction is observable once the frequency with which nouns occur in morphosyntactic contexts is controlled and there is no influence of visual presentation of stimuli. Second, the study was designed to explore whether the use of mass morphosyntax relates to the development of abstraction abilities in 5- to 6-year-old preschool children.

Five- to six-year-old children have completed the acquisition of basic grammar structures (e.g., Tomasello, 2003), and, at the same time, their grammaticality judgments are not biased by a normative approach taught in school. Starting from these considerations, we should predict no differences in the performance with mass and count nouns in congruent contexts in this test. However, based on previous literature, we expect participants to perform better in the count incongruent condition than in the mass incongruent condition because of their susceptibility to overextend the count morphosyntax (Gordon, 1985; Barner \& Snedeker, 2005). Importantly, the above hypothesis might not hold true if previous results were driven by differences in the relative frequency of the nouns chosen or biased by the visual presentation of the stimuli, which were eliminated in this study. Finally, because children's abilities concerning conservation and logical operations (referred to as "abstraction abilities" throughout this article) are still developing at this age, we should expect that they influence children's judgments more on mass nouns than on count nouns. To measure such abilities, we administered the Logical Operations and Conservation test (LOC; Vianello \& Marin, 1997). The LOC, standardized for 4- to 8-year-old children, is the most complete test available in Italian to assess abstraction abilities that specifically deal with the capability to recognize entities without relying on their incidental shape boundaries. Specifically, the LOC test assesses conservation as the ability to comprehend that rearranging material does not affect its numerosity, volume, or length. The LOC is made up by several difficulty-graduated tasks 
encompassing Piagetian, post-Piagetian, and cognitivist references (e.g., Case, 1985; Baddeley, 1986; Sternberg, 1988, as cited in Vianello, Lanfranchi, Pulina, \& Bidinost, 2012). The main assumption is that children mastering operational logical thinking are able to recognize when physical quantities are conserved despite their configurational transformations.

\section{Method}

\section{Participants}

Parental informed consent was obtained for 63 children attending the last year of kindergarten to participate in the study. Data from 58 children (females = 32) were included in the analysis. Children were distributed in 10 different classes of the "A. Rosmini" school in Andria (Barletta-Andria-Trani), Italy. None of the 58 participants had a clinical history of specific language impairment or intellectual disability. All the children were native speakers of Italian and were at least 5 years old (age range: $62-76$ months, $M=69.7, S D=3.1$ ).

\section{Procedure}

An experimenter, who was blind to the goals of the study, tested each participant individually in a silent room in two testing sessions. Participants completed the Mass and Count Test (MACT) along with the Logical Operations and Conservation test (LOC; Vianello \& Marin, 1997) that assesses children's abstraction abilities. Additionally, the Test of Grammatical Comprehension (TCGB; Chilosi \& Cipriani, 1995) was used as a screening measure of morphosyntactic comprehension.

\section{Materials}

Mass and Count Test (MACT) We developed an experimental task to test the children's competence with respect to occurrences of nouns in mass or in count morphosyntactic context. Different from previous studies, items were carefully selected for frequency with respect to their occurrence in mass and count morphosyntax.

We chose nouns inflected only in the singular, and not in the plural, because plurals are only related to a count interpretation. Conversely, singulars can be linked to either a count or a mass interpretation depending on the syntactic context, thus providing an unbiased testing ground. Moreover, we chose syntactic contexts (determiner + noun inflected in the singular) in which mass or count interpretation is unambiguous: in the count context, the determiner was the indeterminate article, corresponding to the numeral one, (e.g., un anello "a ring" vs. *una sabbia "a sand"), in the mass context the determiner was a quantifier (e.g., tanta sabbia "much sand" vs. *tanto anello "much ring").

To balance the frequency, we used a corpus query performed on the ItWaC corpus ( 2 billion tokens corpus made up of texts from Italian websites; Baroni, Bernardini, Ferraresi, \& Zanchetta, 2009) to select nouns used mostly in mass context, nouns used mostly in count context, and nouns used as frequently both in mass and count contexts. Nouns were obtained from a previous subjective frequency rating study by Zanini et al. (2014) and were matched for frequency. Only high-frequency nouns denoting concrete referents were selected.

The age of acquisition of the experimental nouns were controlled by means of a dedicated study. We followed the most broadly used methodology for assessing age of acquisition in Italian psycholinguistic studies (e.g., Barca, Burani, \& Arduino, 2002; Lotto, Dell'Acqua, \& Job, 2001; Nisi, Longoni, \& Snodgrass, 2000; Reverberi, Capitani, \& Laiacona, 2004; for a more recent study on Italian and other languages, see Łuniewska et al., 2015). Eighty-four native speakers of Italian (females $=71$, age range: $18-51, M=21.70)$ were asked to evaluate their age of acquisition of 224 words, including the 40 words used in this study. The questionnaires were administered online by means of Survey Monkey (www.surveymonkey.com); each participant saw a different randomized order of the words. Data are reported in the Appendix Table 2. All nouns had been acquired by the age of 5 or 6 , at least by $95 \%$ of the participants. The age of acquisition was balanced across types of nouns (count nouns: $97.73 \%$; mass nouns: $98.8 \%$; neutral nouns: $96.48 \%$ ). Nouns were also controlled for syllabic length (count nouns: $M$ $=2.5$; mass nouns: $M=2.3$; neutral nouns: $M=2.6$ ).

The items chosen for the MACT were (i) "mass": 10 nouns that appear more frequently in a mass context and are not frequent in a count context (e.g., sand) and (ii) "count": 10 nouns that appear more frequently in a count context and are not frequent in a mass context (e.g., ring). For each noun, two identical sentences were created: in one the noun appeared in a mass context, in the other one, in a count context (see Table 1). As a result, 20 sentences were not well-formed (incongruent condition): in half of them, a mass noun occurred in count context, and in the other half a count noun occurred in mass context. Twenty sentences were well-formed (congruent condition): in half of them a mass noun occurred in mass context, and in the other half a count noun occurred in count context.

Additionally we chose 20 "neutral" nouns, namely nouns that appear in mass and count contexts with similar frequency (e.g., cake). Children's responses to neutral 
Table 1 Experimental conditions

\begin{tabular}{lll}
\hline & Mass context & Count context \\
\hline Mass noun & CONGRUENT & INCONGRUENT \\
& Leo ha tanta sabbia nelle scarpe. & Leo ha una sabbia nelle scarpe. \\
Leo has much sand in his shoes & Leo has a sand in his shoes \\
Count noun & CONGRUENT \\
& La principessa ha un po' di anello al dito. & La principessa ha un anello al dito. \\
Neutral noun & The princess has a bit of ring on her finger & The princess has a ring on her finger \\
& CONGRUENT & CONGRUNT \\
& Sul tavolo c'era ancora tanta torta. & Sul tavolo c'era ancora una torta. \\
& Lit. There was still much cake on the table & There was still a cake on the table \\
\hline
\end{tabular}

nouns are not influenced by the frequency with which they have listened to a noun in a particular context, as such they allow us to measure the participants' response in the absence of this cue. The neutral nouns appeared in 40 sentences. Based on the frequency of occurrence of these nouns in the corpus, the sentences should be considered congruent both in mass and in count context (see Table 1). The experimental material was therefore made up of 80 sentences (see Appendix Table 3).

The sentences were read aloud by a male native Italian speaker, audio recorded, and presented offline to the participants one at the time. The sentences were grouped in two blocks, with each noun occurring only once per block. Each block was administered in a different testing session. The order of presentation of the sentences was pseudorandomized, with no more than four incongruent sentences in a row. Four different pseudorandom orders were produced.

Participants received the following instructions: "Simone is a boy who is learning Italian. Could you please help him? You will listen to some sentences uttered by Simone: some are right and some are wrong. After each sentence, you have to tell me if the sentence was right or wrong."

Each congruent sentence accepted and each incongruent sentence refused scored one point; each congruent sentence refused and incongruent sentence accepted scored zero points. Each answer of the participants was transcribed by the experimenter. When the participant refused a sentence, he or she was asked to produce what he or she considered to be the correct version of the sentence.

A brief training session was administered before the actual test to make sure that the participants had correctly understood the task and, in particular, that they did not express moral judgments on the sentence content instead of acceptability judgments. The sentences used in the training session were six, four grammatical and two not grammatical, and were not included in the experimental material. The procedure was the same as described for the experimental task.
The Logical Operations and Conservation test (LOC; Vianello \& Marin, 1997) This standardized test assesses logical and abstraction abilities in children. It consists of 24 tasks of increasing difficulty divided into four areas: (i) seriation, which consists in ordering objects of different size; (ii) numeration, which requires children to recognize the equal numerosity of two sets of objects; (iii) classification, which consists in grouping together objects by size, color, or form; (iv) conservation, which consists in recognizing whether the amount of an agreed sample of liquid (or dough) is still the same after the experimenter changed its shape by pouring it in another different container (or by remolding it).

The scores were within the normal range for the age of the participants $(M=13.46, S D=4.02)$.

Test of grammatical comprehension (Test di Comprensione Grammaticale del Bambino - TCGB; Chilosi \& Cipriani, 1995) This test requires participants to match 76 sentences of increasing complexity with one out of four pictures. It evaluates the comprehension of the sentence and the acquisition of grammatical structures. We chose to use TCGB as a screening test to make sure that participants master syntactic elaborations in line with their age. The TCGB scores were within the normal range for all the participants $(M=15.83, S D=6.53)$.

\section{Data analysis}

The children's performance on the MACT was evaluated using a $2 \times 2$ ANOVA, with condition (congruent and incongruent) and noun (mass and count) as within-subject factors.

The comparison of the children's ratings on neutral nouns in mass versus count context was carried out separately, using paired $t$ tests. We also used $t$ tests to compare the children's performance on neutral nouns with respect to chance level $(50 \%)$ in each of the contexts. 
Pearson's correlations between the children's performance on each noun-condition of the MACT (e.g., mass congruent, count incongruent) and the LOC were carried out to determine the implication of children's abstraction abilities. To make sure that the relationships between those measures were not mediated by a general demographic factor, we computed partial correlations in which children's age, gender, and class were controlled for.

\section{Results}

The ANOVA analysis showed a main effect of context, $F(1$, $232)=5.30, p<.03$; a main effect of noun, $F(1,232)=15.99$, $p<.001$; and a significant interaction between both factors, $F(1,232)=39.71, p<.0001$. There was a significant difference between mass nouns $(M=51.2 \%, S D=25.2)$ and count nouns $(M=80.0 \%, S D=16.1)$ in the incongruent condition $(p<.0001)$. No significant difference was found in the congruent condition (mass nouns $M=75.2 \%, S D=19.4$; count nouns $M=68.8 \%, S D=24.0 ; p>.05)$. Results are displayed in Fig. 1.

The children's performance on neutral nouns was significantly above chance both in the mass, $t(57)=6.00, p<.001$, and count contexts, $t(57)=11.68, p<.001$; however, a direct comparison of the two conditions showed that children were significantly more accurate in the count context $(M=78.44 \%$, $S D=18.54)$ than in the mass context $(M=63.96 \%, S D=$ 17.71), $t(58)=5.47, p<.0001$ (see Fig. 2).

Finally, the results of the Pearson's correlation analysis showed that participants' performance on mass contexts and the children's abstraction abilities - as measured by the LOC - were intercorrelated (mass nouns in mass contexts, $r$ $=.27 ; p<.05$; count nouns in mass contexts showed a similar tendency, $r=.24 ; p=.07$ ). By contrast, participants' performance on count contexts did not correlate with the measures of abstraction (mass nouns in count contexts, $r=.13 ; p=.35$; count nouns in count contexts, $r=.12 ; p=.36$ ).

\section{Discussion}

The first goal of this study was to evaluate the effects of frequency and verbal presentation over the mass and count distinction. To our knowledge, previous studies have not controlled the actual occurrence of nouns as mass or as count, although some studies have exploited novel words, thus preventing the effects of frequency (e.g., Soja, 1992). In our study, real Italian words were chosen and, for the first time, the mass and count experimental nouns were categorized considering their distribution with respect to mass and count morphosyntactic contexts. Quantitative methods were used to avoid possible biases due to the arbitrary selection of the

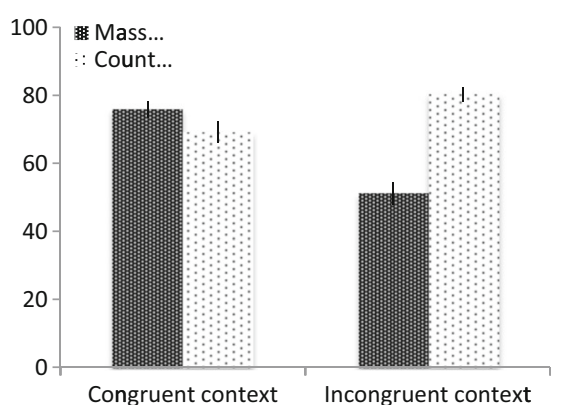

Fig. 1 Children's performance on the MACT. The $y$-axis shows the percentage of correctly accepted sentences in the congruent condition and correctly rejected sentences in the incongruent condition for each noun type

stimuli. Moreover, the study was designed to investigate the relation between the development of abstraction abilities and the use of nouns in mass and count morphosyntax in 5-6-yearold children.

As a first result, data from the children's performance on the MACT showed that the distinction between mass and count nouns still emerges in certain conditions, even after having controlled for frequency and prevented the possible bias of a visual presentation of the stimuli. On the one hand, there is no difference between mass nouns and count nouns in congruent morphosyntactic contexts, thus suggesting that neither of the two conditions is per se more difficult than the other at this age. On the other hand, a predilection for count context emerges in the incongruent condition. Even though a similar result has been previously reported in the literature (Barner $\&$ Snedeker, 2005), for the first time, our study shows that the performance in the incongruent mass condition (i.e., children accepting mass nouns in count context) cannot be explained assuming a frequency effect. If that was the case, an equally bad performance with count nouns in mass context would have occurred. In fact, in the case of low frequency of occurrence with respect to one particular context, we found that mass nouns in count context were widely more accepted with respect to the converse case, even if the sentence was not well formed according to the normative grammar. Notably, Semenza, Mondini, and Cappelletti (1997) found a similar pattern in a patient who preferred sentences in which mass nouns were used in count syntax. A frequency effect is not

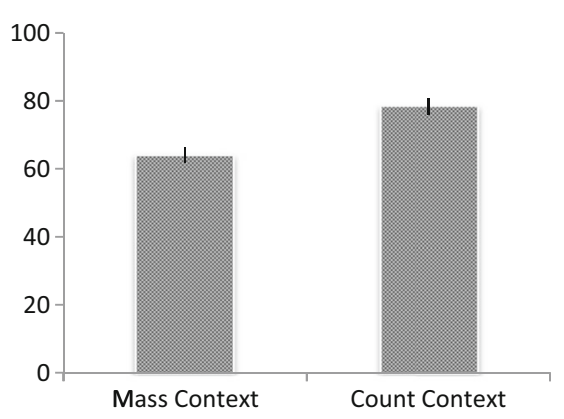

Fig. 2 Percentage of correct responses with neutral nouns 
explicative of the performance with neutral nouns either because they occur as frequently in both morphosyntactic contexts. Even in this case, nouns in a mass context are accepted less than in count context.

Overall, these results suggest an effect of the frequency of occurrence in judging correctly a noun in its proper context, both for mass and for count morphosyntax. In all the other conditions, there is a strong preference for count nouns and count morphosyntax. These trends are consistent with results in the previous literature and cannot be explained in terms of frequency, nor in terms of a specific linguistic difficulty of the mass nouns or morphosyntax.

Thus, a possible explanation for this pattern of results seems not to be related with a mere linguistic feature. Therefore, we explored the hypothesis that, in absence of frequency effects, the mass reference is less preferred because it requires more abstraction abilities related to the logical and conservation operations, namely the ones that allow to recognize entities without relying on their incidental shape boundaries and to comprehend that rearranging material does not affect its intrinsic properties. The literature reports the strong role played by the perceptual (or shape) bias in the acquisition and categorization of novel words (e.g., Landau, Smith, \& Jones, 1988, 1992). This means that the perceived boundaries of an entity are particularly salient in recalling a noun associated to that entity. This may suggest that parsing a (concrete) noun in a phrase is easier when the reference to the boundaries is explicit, as in the case of count morphosyntax. Conversely, parsing a noun in a phrase may be more demanding when the reference to the boundary is suppressed, as in the case of mass morphosyntax.

In this study we found that measures of abstraction abilities (assessed by means of the LOC test) correlated with the performance in mass contexts, both in congruent and incongruent conditions. In other words, the better the children performed in the LOC test the more they accepted mass nouns in mass context and refused count nouns in mass context. On the contrary, no correlation was found between children's performance in the LOC and their performance in the MACT for what concerns count context.

The data concerning the aforementioned correlations between children's' performance in the MACT and in the LOC test are consistent with the hypothesis illustrated above, and they can offer the basis for a possible explanation of the children's disfavor of mass morphosyntax in an incongruent condition. Because the LOC assesses the capability of dealing with abstract and logical operations, and because there is a positive correlation between the LOC score and the performance on mass contexts, it may be the case that the logical and conservation abilities are more involved in the processing of a more abstract reference as the mass one. Thus, children preferred count morphosyntax in the incongruent condition because a mass interpretation refers to a conceiving of the entity independent from its shape, and the cognitive abilities underpinning this conception are not yet fully disposable at the age of 5 (i.e., Vianello \& Marin, 1997).

Remarkably, the LOC scores do not correlate with children's performance in count context. This result may point to the fact that parsing nouns in count context does not require the type of abstraction abilities concerning uncountability.

Noteworthy, even if children did not complete the development of the abstraction abilities at this age, they performed well with mass morphosyntax in congruent condition. This is likely because they could base their judgments on the frequency of occurrence of the nouns in the surrounding language. Conversely, in the incongruent condition, they had no cue of any type and, as a result, they performed worse in mass context.

\section{Conclusions}

The most traditional accounts assume the mass and count distinction to be linguistic in nature, with mass reference associated with less formal features. Based on the current findings, we argue that the difference between these two categories can be explained in terms of an interaction between language and extralinguistic abstraction abilities. These latter allow to recognize entities without relying on their incidental shape boundaries, namely, the ones responsible of logical and conservation operations. The distinction at the cognitive level appears associated to more (and not less) processing of mass properties with respect to count properties. These results suggest that the representation of uncountability is more effortful because it requires additional abstraction abilities with respect to the ones needed in representing countability. Our study also indicates that when the relative frequency of use is controlled, such distinction - apparently intrinsic of language - is no longer so clear-cut, suggesting that linguistic features alone are not sufficient to define it.

Acknowledgments The research presented in this article was supported in part by a research fellow grant CPDR 149779 (University of Padova) to the first author. The funding source had no other role other than financial support.

We would like to thank all the teachers of the school "A. Rosmini" of Andria (BT), and in particular the headmistress Celestina Martinelli. We also would like to thank the children that participated with enthusiasm to this study and their parents who agreed to their participation. Many thanks to Mariangela Lomuscio for helping with the collection of data, to Simone Crespan for helping with the audiorecording of the MACT sentences, and to Carlo Semenza for useful comments on previous versions of this manuscript. 


\section{Appendix 1}

Table 2 Age of acquisition of the experimental words (count, mass and neutral nouns). The number refers to the percentage of participants in the rating that had acquired the noun at the age indicated in the corresponding header

\begin{tabular}{|c|c|c|c|c|c|c|c|c|c|c|}
\hline \multirow[b]{2}{*}{ Count nouns } & \multicolumn{10}{|c|}{ Age of acquisition (years) } \\
\hline & -2 & $2-3$ & $3-4$ & $4-5$ & $5-6$ & $6-8$ & $8-10$ & $10-12$ & $13-$ & $\begin{array}{l}\text { Not } \\
\text { known }\end{array}$ \\
\hline Anello & 9.52 & 41.66 & 73.80 & 92.85 & 94.04 & 96.42 & 98.80 & 98.80 & 100 & 0 \\
\hline \multicolumn{11}{|l|}{ Ring } \\
\hline Biscotto & 48.81 & 80.95 & 96.43 & 98.81 & 100 & 100 & 100 & 100 & 100 & 0 \\
\hline \multicolumn{11}{|l|}{ Cookie } \\
\hline Caramella & 39.29 & 73.81 & 94.05 & 97.62 & 100 & 100 & 100 & 100 & 100 & 0 \\
\hline \multicolumn{11}{|l|}{ Sweet/Candy } \\
\hline Cerotto & 10.71 & 48.81 & 77.38 & 88.09 & 92.85 & 96.42 & 97.61 & 98.80 & 98.80 & 1.19 \\
\hline \multicolumn{11}{|l|}{ Patch } \\
\hline Foglia & 28.57 & 59.52 & 90.47 & 97.61 & 100 & 100 & 100 & 100 & 100 & 0 \\
\hline \multicolumn{11}{|l|}{ Leaf } \\
\hline Sasso & 36.9 & 71.42 & 86.90 & 96.42 & 100 & 100 & 100 & 100 & 100 & 0 \\
\hline \multicolumn{11}{|l|}{ Stone } \\
\hline Fungo & 10.71 & 39.28 & 74.99 & 88.09 & 97.61 & 98.80 & 100 & 100 & 100 & 0 \\
\hline \multicolumn{11}{|l|}{ Mushroom } \\
\hline Sciarpa & 5.95 & 32.14 & 67.85 & 90.47 & 95.23 & 100 & 100 & 100 & 100 & 0 \\
\hline \multicolumn{11}{|l|}{ Scarf } \\
\hline Tazza & 22.62 & 53.57 & 80.95 & 91.66 & 98.80 & 100 & 100 & 100 & 100 & 0 \\
\hline \multicolumn{11}{|l|}{ Cup } \\
\hline Uovo & 26.19 & 67.86 & 83.34 & 94.05 & 98.81 & 100 & 100 & 100 & 100 & 0 \\
\hline \multicolumn{11}{|l|}{ Egg } \\
\hline \multicolumn{11}{|l|}{ Mass nouns } \\
\hline Burro & 16.67 & 50 & 75 & 86.9 & 94.04 & 97.61 & 100 & 100 & 100 & 0 \\
\hline \multicolumn{11}{|l|}{ Butter } \\
\hline Carne & 33.33 & 69.04 & 86.9 & 95.23 & 98.8 & 100 & 100 & 100 & 100 & 0 \\
\hline \multicolumn{11}{|l|}{ Meat } \\
\hline Ghiaccio & 8.33 & 35.71 & 70.23 & 82.13 & 97.61 & 98.8 & 100 & 100 & 100 & 0 \\
\hline \multicolumn{11}{|l|}{ Ice } \\
\hline Latte & 60.71 & 84.52 & 95.23 & 96.42 & 98.8 & 100 & 100 & 100 & 100 & 0 \\
\hline Milk & & & & & & & & & & \\
\hline Miele & 16.67 & 46.43 & 72.62 & 83.33 & 96.43 & 98.81 & 100 & 100 & 100 & 0 \\
\hline Honey & & & & & & & & & & \\
\hline Polenta & 3.57 & 25 & 50 & 73.81 & 86.91 & 94.05 & 96.43 & 100 & 100 & 0 \\
\hline Cornmush & & & & & & & & & & \\
\hline Polvere & 4.76 & 20.24 & 52.38 & 77.38 & 90.48 & 97.62 & 100 & 100 & 100 & 0 \\
\hline Dust & & & & & & & & & & \\
\hline Pane & 63.1 & 84.53 & 94.05 & 98.81 & 100 & 100 & 100 & 100 & 100 & 0 \\
\hline Bread & & & & & & & & & & \\
\hline Zucchero & 25 & 54.76 & 82.14 & 92.85 & 97.61 & 98.8 & 100 & 100 & 100 & 0 \\
\hline Sugar & & & & & & & & & & \\
\hline Sabbia & 35.71 & 67.85 & 91.66 & 97.61 & 98.8 & 100 & 100 & 100 & 100 & 0 \\
\hline Sand & & & & & & & & & & \\
\hline Neutral nouns & & & & & & & & & & \\
\hline Frittata & 3.57 & 30.95 & 54.76 & 83.33 & 94.04 & 100 & 100 & 100 & 100 & 0 \\
\hline Omelet & & & & & & & & & & \\
\hline Anguria & 9.52 & 32.14 & 64.28 & 85.71 & 94.04 & 97.61 & 98.8 & 98.8 & 98.8 & 1.19 \\
\hline Watermelon & & & & & & & & & & \\
\hline Aranciata & 7.14 & 39.28 & 74.99 & 91.66 & 96.42 & 100 & 100 & 100 & 100 & 0 \\
\hline Orange Soda & & & & & & & & & & \\
\hline Banana & 42.86 & 69.05 & 92.86 & 97.62 & 100 & 100 & 100 & 100 & 100 & 0 \\
\hline Banana & & & & & & & & & & \\
\hline Bistecca & 11.9 & 39.28 & 55.95 & 80.95 & 91.66 & 100 & 100 & 100 & 100 & 0 \\
\hline Steak & & & & & & & & & & \\
\hline Carta & 27.38 & 59.52 & 88.09 & 100 & 100 & 100 & 100 & 100 & 100 & 0 \\
\hline
\end{tabular}


Table 2 (continued)

Age of acquisition (years)

\begin{tabular}{|c|c|c|c|c|c|c|c|c|c|c|}
\hline \multicolumn{11}{|l|}{ Paper } \\
\hline Corda & 5.95 & 26.19 & 63.09 & 86.9 & 96.42 & 100 & 100 & 100 & 100 & 0 \\
\hline \multicolumn{11}{|l|}{ Rope } \\
\hline Dentifricio & 3.57 & 38.09 & 60.71 & 83.33 & 95.23 & 97.61 & 100 & 100 & 100 & 0 \\
\hline \multicolumn{11}{|l|}{ Toothpaste } \\
\hline Gelato & 33.33 & 78.57 & 88.09 & 97.61 & 97.61 & 98.8 & 100 & 100 & 100 & 0 \\
\hline \multicolumn{11}{|l|}{ Ice-cream } \\
\hline Gomma & 7.14 & 39.28 & 71.42 & 92.85 & 98.8 & 98.8 & 98.8 & 100 & 100 & 0 \\
\hline \multicolumn{11}{|l|}{ Bubble gum } \\
\hline Mela & 46.43 & 73.81 & 94.05 & 100 & 100 & 100 & 100 & 100 & 100 & 0 \\
\hline \multicolumn{11}{|l|}{ Apple } \\
\hline Minestra & 20.24 & 55.95 & 86.9 & 96.42 & 98.8 & 100 & 100 & 100 & 100 & 0 \\
\hline \multicolumn{11}{|l|}{ Soup } \\
\hline Pelo & 11.9 & 40.47 & 59.52 & 80.95 & 95.24 & 97.62 & 98.81 & 100 & 100 & 0 \\
\hline \multicolumn{11}{|l|}{ Fur } \\
\hline Moneta & 7.14 & 28.57 & 57.14 & 78.57 & 95.24 & 97.62 & 100 & 100 & 100 & 0 \\
\hline \multicolumn{11}{|l|}{ Coin/Money } \\
\hline Prosciutto & 16.67 & 51.19 & 78.57 & 88.09 & 96.42 & 100 & 100 & 100 & 100 & 0 \\
\hline \multicolumn{11}{|l|}{ Ham } \\
\hline Pizza & 22.62 & 59.52 & 86.9 & 97.61 & 100 & 100 & 100 & 100 & 100 & 0 \\
\hline \multicolumn{11}{|l|}{ Pizza } \\
\hline Roccia & 7.14 & 27.38 & 54.76 & 73.81 & 90.48 & 97.62 & 98.81 & 100 & 100 & 0 \\
\hline \multicolumn{11}{|l|}{ Rock } \\
\hline Salame & 8.33 & 41.66 & 63.09 & 85.71 & 92.85 & 98.8 & 100 & 100 & 100 & 0 \\
\hline \multicolumn{11}{|l|}{ Salami } \\
\hline Vetro & 9.52 & 33.33 & 63.09 & 84.52 & 96.42 & 98.8 & 98.8 & 100 & 100 & 0 \\
\hline \multicolumn{11}{|l|}{ Glass } \\
\hline Torta & 36.9 & 75 & 91.67 & 96.43 & 100 & 100 & 100 & 100 & 100 & 0 \\
\hline Cake & & & & & & & & & & \\
\hline
\end{tabular}

\section{Appendix 2}

Table 3 Experimental trials

Mass nouns in mass contexts:

Nel frigorifero c'è un po' di burro.

Il papà ha cucinato molta carne.

Attento! C'è del ghiaccio per terra!

Il bambino ha bevuto del latte.

Queste api fanno molto miele.

La mamma ha comprato del pane.

Il nonno ha mangiato molta polenta.

Sotto il letto c'è tanta polvere.

Leo ha tanta sabbia nelle scarpe.

Nel barattolo è rimasto poco zucchero.

\section{Count nouns in mass contexts:}

La principessa ha un po' di anello al dito.

Il cane ha mangiato molto biscotto.

Il bambino mangia molta caramella.

Sara ha tanto cerotto sul braccio.

La bambina ha raccolto poca foglia.

Lo zio ha trovato del fungo nel bosco.

Mattia ha lanciato un po' di sasso nel lago.
Mass nouns in count contexts:

Nel frigorifero c'è un burro.

Il papà ha cucinato una carne.

Attento! C'è un ghiaccio per terra!

Il bambino ha bevuto un latte.

Queste api fanno un miele.

La mamma ha comprato un pane.

Il nonno ha mangiato una polenta.

Sotto il letto c'è una polvere.

Leo ha una sabbia nelle scarpe.

Nel barattolo è rimasto uno zucchero.

\section{Count nouns in count contexts:}

La principessa ha un anello al dito.

Il cane ha mangiato un biscotto.

Il bambino mangia una caramella.

Sara ha un cerotto sul braccio.

La bambina ha raccolto una foglia.

Lo zio ha trovato un fungo nel bosco.

Mattia ha lanciato un sasso nel lago. 
Table 3 (continued)

Il pupazzo ha addosso molta sciarpa.

Il cameriere ha rotto tanta tazza.

La gallina ha fatto poco uovo.

Neutral nouns in mass contexts:

Quest'estate Andrea ha mangiato tanta anguria.

La bambina beve molta aranciata.

Nel frullato c'era poca banana.

Il cane ha mangiato un po' di bistecca.

Il bidello ha raccolto tanta carta.

Sulla nave c'è tanta corda.

La mamma ha comprato del dentifricio.

La tata ha cucinato tanta frittata.

$\mathrm{Nel}$ freezer c'è ancora molto gelato.

Ho masticato tanta gomma.

Biancaneve ha mangiato un po' di mela.

La nonna prepara un po' di minestra.

Giacomo ha tanta moneta nel salvadanaio.

C'era del pelo sul tappeto.

Il fornaio ha impastato tanta pizza.

Il salumiere affetta tanto prosciutto.

I nani spaccano molta roccia.

Giulia fa merenda con un po' di salame.

Sul tavolo c'era ancora tanta torta.

Attento, c'è del vetro sul pavimento!
Il pupazzo ha addosso una sciarpa.

Il cameriere ha rotto una tazza.

La gallina ha fatto un uovo.

Neutral nouns in count contexts:

Quest'estate Andrea ha mangiato un'anguria.

La bambina beve un'aranciata.

Nel frullato c'era una banana.

Il cane ha mangiato una bistecca.

Il bidello ha raccolto una carta.

Sulla nave c'è un po' di corda.

La mamma ha comprato un dentifricio.

La tata ha cucinato una frittata.

$\mathrm{Nel}$ freezer c'è ancora un gelato.

Ho masticato una gomma.

Biancaneve ha mangiato una mela.

La nonna prepara una minestra.

Giacomo ha una moneta nel salvadanaio.

C'era un pelo sul tappeto.

Il fornaio ha impastato una pizza.

Il salumiere affetta un prosciutto.

I nani spaccano una roccia.

Giulia fa merenda con un salame.

Sul tavolo c'era ancora una torta.

Attento, c'è un vetro sul pavimento.

\section{References}

Allan, K. (1980). Nouns and countability. Language, 56, 541-567. Baddeley, A. D. (1986). Working memory. Oxford: Clarendon Press.

Bale, A., \& Barner, D. (2009). The interpretation of functional heads: Using comparatives to explore the mass/count distinction. Journal of Semantics, 26, 217-252.

Barca, L., Burani, C., \& Arduino, L. S. (2002). Word naming times and psycholinguistic norms for Italian nouns. Behavior Research Methods, Instruments, \& Computers, 34(3), 424-434.

Barner, D., \& Snedeker, J. (2005). Quantity judgments and individuation: Evidence that mass nouns count. Cognition, 97, 41-66.

Barner, D., \& Snedeker, J. (2006). Children's early understanding of masscount syntax: Individuation, lexical content, and the number asymmetry hypothesis. Language Learning and Development, 2(3), 163-194.

Baroni, M., Bernardini, S., Ferraresi, A., \& Zanchetta, E. (2009). The WaCky Wide Web: A collection of very large linguistically processed web-crawled corpora. Language Resources and Evaluation, 43(3), 209-226.

Bloom, P. (1999). The role of semantics in solving the bootstrapping problem. In R. Jackendoff, P. Bloom, \& K. Wynn (Eds.), Language, logic and concepts: Essays in memory of John Macnamara. Cambridge: MIT Press.

Bloom, P., \& Kelemen, D. (1995). Syntactic cues in the acquisition of collective nouns. Cognition, 56, 1-30.

Borer, H. (2005). In name only. Oxford: OUP.

Case, R. (1985). Intellectual development from birth to adulthood. New York: Academic Press.

Cheng, C. Y. (1973). Response to Moravcsik. In J. Hintikka, J. M. E. Moravcsik, \& P. Suppes (Eds.), Approaches to natural language (pp. 286-288). Dordrecht: Reidel.

Chesney, D. L., \& Gelman, R. (2015). What counts? Visual and verbal cues interact to influence what is considered a countable thing. Memory \& Cognition, 43(5), 798-810.

Chierchia, G. (1998). Plurality of mass nouns and the notion of 'semantic parameter'. In S. Rothstein (Ed.), Events and grammar (pp. 53103). Dordrecht: Kluwer.
Chierchia, G. (2010). Mass nouns, vagueness and semantic variation. Synthese, 174, 99-149.

Chilosi, A. M., \& Cipriani, P. (1995). Test di Comprensione Grammaticale per Bambini [Grammatical comprehension test for Children]. Pisa: Edizioni Del Cerro.

De Belder, M. (2011). A morphosyntactic decomposition of countability in Germanic. Journal of Comparative Germanic Linguistics, 14(3), 173-202.

El Yagoubi, R., Mondini, S., Bisiacchi, P., Chiarelli, V., Angrilli, A., \& Semenza, C. (2006). The elctrophysiological basis of mass and count nouns. Brain and Language, 99, 187-188.

Frisson, S., \& Frazier, L. (2005). Carving up word meaning: Portioning and grinding. Journal of Memory and Language, 53(2), 277-291.

Gathercole, V. C. (1985). He has too much hard questions: The acquisition of the linguistic mass-count distinction in much and many. Journal of Child Language, 12(2), 395-415.

Gillon, B. (1992). Towards a common semantics for English count and mass nouns. Linguistic and Philosophy, 15, 597-639.

Gillon, B., Kehayia, E., \& Taler, V. (1999). The mass/count distinction: Evidence from on-line psycholinguistic performance. Brain and Language, 68, 205-211.

Gordon, P. (1985). Evaluating the semantic categories hypothesis: The case of the count/mass distinction. Cognition, 20(3), 209-242.

Hespos, S. J., Ferry, A. L., \& Rips, L. J. (2009). Five-month-old infants have different expectations for solids and liquids. Psychological Science, 20(5), 603-611.

Hespos, S. J., \& vanMarle, K. (2012). Physics for infants: Characterizing the origins of knowledge about objects, substances, and number. Wiley Interdisciplinary Reviews: Cognitive Science, 3(1), 19-27.

Imai, M., \& Gentner, D. (1997). A cross-linguistic study of early word meaning: Universal ontology and linguistic influence. Cognition, 62(2), 169-200.

Jackendoff, R. (1991). Parts and boundaries. Cognition, 41, 9-45.

Katz, G., \& Zamparelli, R. (2012). Quantifying count/mass elasticity. In J. Choi et al. (Eds.), Proceedings of the 29th west coast conference on formal linguistics (pp. 371-379). Somerville: Cascadilla Proceedings Project. 
Kulkarni, R., Rothstein, S., \& Treves, A. (2013). A statistical investigation into the cross-linguistic distribution of mass and count nouns: Morphosyntactic and semantic perspectives. Biolinguistics, 7, 132168.

Landau, B., Smith, L. B., \& Jones, S. S. (1988). The importance of shape in early lexical learning. Cognitive Development, 3(3), 299-321.

Landau, B., Smith, L. B., \& Jones, S. (1992). Syntactic context and the shape bias in children's and adults' lexical learning. Journal of Memory and Language, 31(6), 807-825.

Lotto, L., Dell'Acqua, R., \& Job, R. (2001). Le figure PD/DPSS. Misure di accordo sul nome, tipicità, familiarità, età di acquisizione e tempi di denominazione per 266 figure [PD/DPSS Pictures. Agreement measures on nouns, familiarity, age of acquisition and naming times for 266 pictures]. Giornale Italiano di Psicologia, 28(1), 193-207.

Łuniewska, M., Haman, E., Armon-Lotem, S., Etenkowski, B., Southwood, F., Anđelković, D., \& Gagarina, N. (2015). Ratings of age of acquisition of 299 words across 25 languages: Is there a crosslinguistic order of words? Behavior Research Methods, 48(3), 1154-1177.

Markman, E. M. (1990). Constraints children place on word meanings. Cognitive Science, 14, 57-77.

Middleton, E. L., Wisniewski, E. J., Trindel, K. A., \& Imai, M. (2004). Separating the chaff from the oats: Evidence for a conceptual distinction between count noun and mass noun aggregates. Journal of Memory and Language, 50(4), 371-394.

Mondini, S., Angrilli, A., Bisiacchi, P., Spironelli, C., Marinelli, K., \& Semenza, C. (2008). Mass and count nouns activate different brain regions: An ERP study on early components. Neuroscience Letters, $430,48-53$

Mondini, S., Kehaya, E., Gillon, B., Arcara, G., \& Jarema, G. (2009). Lexical access of mass and count nouns. How word recognition reaction times correlate with lexical and morphosyntactic processing. The Mental Lexicon, 4, 354-379.

Nisi, M., Longoni, A. M., \& Snodgrass, J. G. (2000). Misure italiane per l'accordo sul nome, familiarità ed età di acquisizione, per le 260 figure di Snodgrass e Vanderwart (1980) [Agreement measures of Italian nouns, familiarity and age of acquisition for the 260 Snodgrass and Vanderwart's testing pictures ]. Giornale Italiano di Psicologia, 27, 205-218.

Pelletier, F. J. (1975). Non-singular reference: Some preliminaries. Philosophia, 5, 451-465.

Pelletier, F. J. (2012). Lexical nouns are neither mass nor count, but they are both mass and count. In D. Massam (Ed.), Count and mass across languages (pp. 9-26). Oxford: Oxford University Press.

Prasada, S., Ferenz, K., \& Haskell, T. (2002). Conceiving of entities as objects and as stuff. Cognition, 83(2), 141-165.

Quine, W. V. O. (1960). Word and object. Cambridge: MIT Press.

Reverberi, C., Capitani, E., \& Laiacona, M. (2004). Variabili semanticolessicali relative a tutti gli elementi di una categoria semantica: Indagine su soggetti normali italiani per la categoria "frutta" [Lexical and semantic variables relative to all elements of a semantic category: a survey on normal Italian subjects respect to the category "fruits"]. Giornale Italiano di Psicologia, 31(3), 497-522.

Rothstein, S. (2010). Counting and the mass/count distinction. Journal of Semantics, 27(3), 343-397.

Samuelson, L. K., \& Horst, J. S. (2007). Dynamic noun generalization: Moment-to-moment interactions shape children's naming biases. Infancy, 11(1), 97-110.

Samuelson, L. K., \& Smith, L. B. (1999). Early noun vocabularies: Do ontology, category structure and syntax correspond? Cognition, 73(1), 1-33.

Semenza, C., El Yagoubi, R., Mondini, S., Chiarelli, V., \& Venneri, A. (2008). Processing of mass and count nouns in the brain. In V. Bambini, I. Ricci, \& P. M. Bertinetto (Eds.), Language and the brain-Semantics. Atti della XLII Congresso Internazionale di Studi della Società di Linguistica Italiana (Vol. 2 I.C.3). Pisa: Bulzoni.

Semenza, C., Mondini, S., \& Cappelletti, M. (1997). The grammatical properties of mass nouns: An aphasia case study. Neuropsychologia, $35,669-675$.

Soja, N. N. (1992). Inferences about the meanings of nouns: The relationship between perception and syntax. Cognitive Development, $7(1), 29-45$.

Soja, N. N., Carey, S., \& Spelke, E. (1991). Ontological categories guide young children's inductions of word meaning: Object terms and substance terms. Cognition, 38, 179-211.

Steinhauer, K., Pancheva, R., Newman, A. J., Gennari, S., \& Ullman, M. T. (2001). How the mass counts: An electrophysiological approach to the processing of lexical features. Cognitive Neuroscience and Neuropsychology, 12(5), 999-1005.

Sternberg, R. J. (1988). The triarchic mind: a new theory of human intelligence. New York: Viking.

Tomasello, M. (2003). Constructing a language: A usage-based theory of language acquisition. Cambridge: Harvard University Press.

vanMarle, K., \& Scholl, B. J. (2003). Attentive tracking of objects versus substances. Psychological Science, 14, 498-504.

vanMarle, K., \& Wynn, K. (2011). Tracking and quantifying objects and non-cohesive substances. Developmental Science, 14(3), 502-515.

Vianello, R., Lanfranchi, S., Pulina, F., \& Bidinost, S. (2012). Italian standardization of the dynamic version of the Logical Operations and Conservation Test (LOC-DV). Life Span and Disability, 15(1), 69-96.

Vianello, R., \& Marin, M. L. (1997). OLC. Dal pensiero intuitivo al pensiero operatorio concreto: Prove per la valutazione del livello di sviluppo [LOC. From intuitive thought to concrete operational thinking: Tests for the assessment of the developmental stages]. Bergamo: Edizioni Junior.

Zanini, C., Arcara, G., \& Franzon, F. (2014). Measuring the distribution of mass and count nouns: A comparison between a rating study and a corpus based analysis (p. 14). Łódź, Poland: Palc. doi:10.13140/RG.2.1.3986.5448 